\title{
Клинико-эндоскопическая диагностика инородных тел бронхов
}

\author{
1 - ГОУ ДПО "Российская медищинская академия последипломного образования": 125284, Москва, 2-й Боткинский пр-д, 7; \\ 2 - ГКБ им. С.П.Боткина: 125284, Москва, 2-й Боткинский пр-д, 5; \\ 3 - ГКБ № 52: 123182, Москва, ул. Пехотная, 3; \\ 4 - клиническая больница "Феофания" Государственного управления делами Президента Украины: 03680, Киев, ул. акад. Заболотного, 21
}

\section{N.E.Chernekhovskaya, I.M.Maltseva, I.Yu.Korsheva, A.V.Povalyaev, G.I.Makarova \\ Clinical and endoscopic detection of foreign bodies in bronchi}

Key words: bronchoscopy, foreign bodies.

Ключевые слова: бронхоскопия, инородные тела.

Удаление инородных тел из бронхов - старейшая проблема бронхопульмонологии. Именно для извлечения инородного тела из правого главного бронха в 1897 г. Г.Киллиан выполнил первую в мире бронхоскопию с помощью ригидного эзофагоскопа. Создание гибких бронхоскопов и видеобронхоскопов, а также наличие в арсенале врачей-эндоскопистов специальных экстракторов открывает широкие возможности для улучшения диагностики инородных тел бронхов [6, 7].

Бронхоскопия при аспирированных инородных телах является не только диагностической, но и лечебной процедурой [9]. Нередко при отсутствии рентгенологических данных и четких анамнестических указаний на возможность аспирации врачи отказываются от проведения бронхоскопии [8]. Многие авторы $[2,5,10]$ указывали на то, что полная окклюзия бронха инородным телом является главной патогенетической причиной стеноза бронха и развития воспалительного процесса в супрастенотическом отделе легкого. Поэтому знание клинической картины позволяет выбрать правильную лечебную тактику и избежать тяжелых осложнений.

Цель работы - оценить данные клинико-рентгенологической симптоматики и эндоскопической картины инородных тел бронхов и разработать лечебную тактику в зависимости от длительности нахождения инородных тел в трахеобронхиальном дереве.

\section{Материалы и методы}

За 24 года при выполнении бронхоскопии инородные тела бронхов были обнаружены у 64 больных $(0,5 \%$ всех диагностических бронхоскопий). Среди обследуемых было 28 мужчин и 36 женщин в возрасте от 24 до 72 лет. Средний возраст составил 44,9 года.

Характер симптоматики зависит от вида инородного тела и длительности его присутствия в бронхах, которая, по нашим данным, может составлять от нескольких часов до 27 лет. Пребывание инородного тела в бронхе $>24$ ч следует считать длительным [1, $3,4]$.

В первые часы после попадания в бронхи инородного тела у 9 больных кашель был постоянным, у 6 приступообразным.

Наибольшие диагностические трудности возникают при давно аспирированных инородных телах, т. к. у больных отсутствуют характерные анамнестические данные. Указания на аспирацию инородного тела имелись лишь у 3 пациентов $(6,1 \%)$.

При длительном пребывании инородного тела в бронхах все больные (100\%) жаловались на постоянный кашель с мокротой. Одышка беспокоила 12 пациентов $(24,5 \%)$, кровохарканье - 38 (77,6 \%), боли в груди были у 5 человек (10,2\%). С предположительным диагнозом инородного тела бронха поступили 3 больных, хронической пневмонии - 13, хронического бронхита -8 , кровохарканья неясной этиологии -22 , рака легкого -2 , бронхиальной астмы - 1 пациент.

\section{Результаты собственных наблюдений}

Всем больным при поступлении выполняли рентгенологическое обследование органов грудной полости, при котором инородные тела были выявлены у 17 (26,6 \%) человек. Это были зубные протезы 5 случаев, зубные коронки - 2, зуб - 1, зубной экстрактор - 2, колпачок от карманного ингалятора -1 , гвоздь -2 , болт -1 , кончик ножа -1 , монета -1 , инъекционная игла -1 .

У 47 больных инородные тела не обнаружены, т. к. они оказались нерентгеноконтрастными. При рентгенологическом обследовании нижнедолевая пневмония диагностирована у 19 (40,4 \%), синдром средней доли - у 6 (12,7 \%), абсцесс нижней доли правого легкого - у 2 (4,3\%), рак легкого - у 2 пациентов $(4,3 \%)$; патологии не выявлено в 18 случаях $(42,6 \%)$. 
Было проведено бронхоскопическое исследование с помощью бронхофиброскопов (Olympus и Fujinon, Япония), а также видеобронхоскопов (Olympus, Fujinon и Pentax, Япония).

Всем больным 1-е эндоскопическое исследование выполняли в бронхоскопическом кабинете, в положении сидя, под местной анестезией 2\%-ным раствором лидокаина с предварительным введением подкожно 1 мл 0,1\%-ного раствора атропина сульфата. Во избежание травмы слизистой оболочки носа и потери извлекаемого предмета в полости ротоглотки эндоскоп вводили трансорально. Осложнений, связанных с диагностической и лечебной бронхоскопией, у больных с инородными телами не было.

Для удаления инородных тел использовали специальные экстракторы (Olympus, Япония; рис. 1). Во время бронхоскопии зубные протезы, инъекционную иглу, зубные экстракторы, гвоздь, болт извлекали с помощью металлической петли. Зубы и зубные коронки удаляли с помощью экстрактора типа "крысиный зуб", колпачок от карманного ингалятора с помощью вилочкового захвата, монету - посредством захвата типа "крокодил".

Показанием к выполнению диагностической бронхоскопии у 27 больных с давно аспирированными инородными телами явился длительный, рецидивирующий нагноительный процесс в легких, не поддающийся традиционной терапии, у 2 пациентов необходимость проведения дифференциального диагноза с центральным раком легкого. 18 больных, у которых на рентгенограммах патологии не выявлено, обратились к врачу в связи с длительным постоянным кашлем и кровохарканьем.

У всех пациентов во время 1-й диагностической бронхоскопии вокруг инородных тел имелся выраженный воспалительный вал, который резко суживал просвет бронха. Кроме того, инородные тела были полностью закрыты грануляциями, которые располагались на стенках главных бронхов у 5 больных, в верхнедолевом бронхе справа - у 1, в промежуточном бронхе справа - у 8, в нижнедолевом бронхе справа - у 10, слева - у 13, в среднедолевом бронхе - у 7, в сегменте $\mathrm{B}_{6}$ слева - у 1 (рис. 2), в В 9 слева - у 1, в $\mathrm{B}_{10}$ слева - у 1 пациента. Грануляции были серого цвета, дольчатые, тусклые, мягкие, лег-

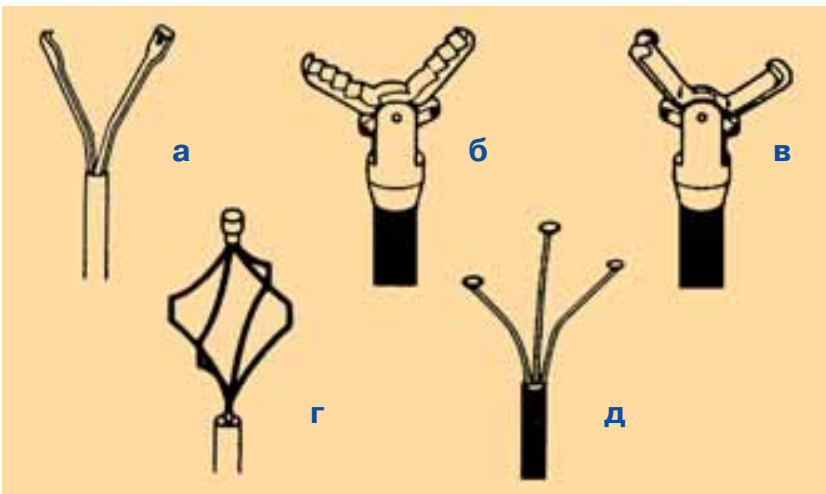

Рис. 1. Инструменты для извлечения инородных тел: а - вилочковый захват; б - экстрактор типа "крокодил"; в - экстрактор типа "крысиный зуб"; г - корзинка Дормиа; д - трехногий захват

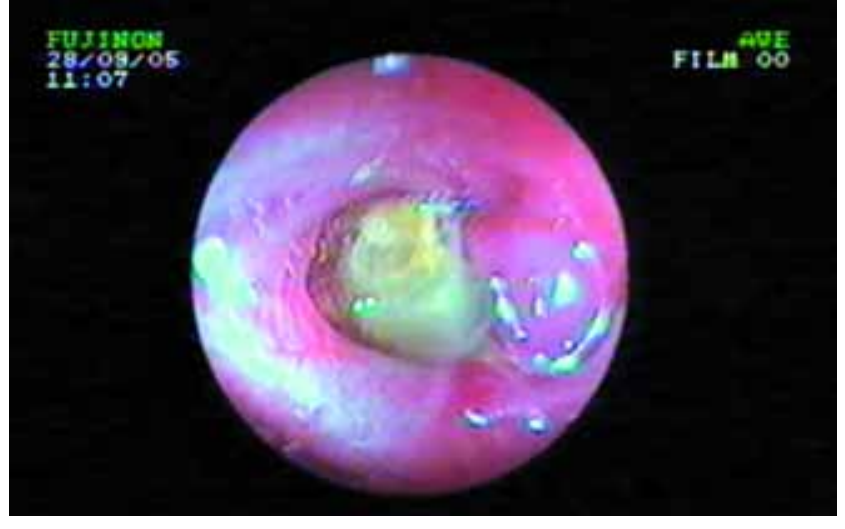

Рис. 2. Инородное тело (зуб) частично закрыто грануляцией

ко кровоточащие при инструментальной пальпации, по внешнему виду очень напоминали опухолевую ткань. При взятии биопсии из грануляций были обнаружены инородные тела.

Фасоль, семена яблока, апельсина, подсолнечника, куски мяса, печени при попадании в бронхи представляют особую опасность, так как, разбухая, обтурируют просвет бронха. Удаление их представляет значительные сложности: при фиксации инструмента такие инородные тела легко фрагментируются. Отечная слизистая оболочка бронха часто травмируется, что вызывает кровотечение во время извлечения и делает невозможным дальнейшее выполнение лечебного эндоскопического вмешательства.

Очень сложна дифференциальная диагностика между давно аспирированным инородным телом и бронхогенным раком.

Приводим наше наблюдение.

Больная Ж., 63 года, поступила с жалобами на кашель с мокротой. Считала себя больной в течение 5 лет. При рентгенологическом исследовании обнаружены уменьшение в объеме нижней доли левого легкого и ателектаз В9. При линейной томографии диагностирован центральный рак нижней доли левого легкого с метастазами в лимфатические узлы. Во время бронхоскопии в левом главном бронхе обнаружено разрастание бугристой ткани серого цвета. Взят смыв на атипичные клетки и микобактерии туберкулеза, результаты биопсии отрицательные. Так как из-под ткани поступал в небольшом количестве гнойный секрет, проведены 3 санационные бронхоскопии, во время которых также выполнялась биопсия (все результаты были отрицательными). Во время 4-го исследования в просвете левого главного бронха обнаружено инородное тело - кость размером $2,0 \times 0,5$ см, которая была удалена с помощью вилочкового захвата. Были проведены еще 2 санационные бронхоскопии. Грануляции исчезли, просвет левого главного бронха восстановлен.

Общепринято мнение, что метод исследования капиллярного кровообращения является неспецифичным. Однако приводимое нами наблюдение в какой-то мере опровергает это положение.

Больная K., 57 лет, наблюдалась в поликлинике по месту жительства в течение 3 лет по поводу бронхиальной астмы и получала соответствующую терапию, которая не давала клинического эффекта. При рентгенологическом исследовании заподозрен стеноз промежуточного бронха справа. Было проведено комплексное радионуклидное исследование легких. После внутривенного введения макроагрегата альбумина (МАА), меченого 99mТс, получено изображение обоих легких с четкими неровными контурами. Вместо ожидаемой картины диффузного поражения органа (по клиническим данным), было выявлено локальное нарушение 


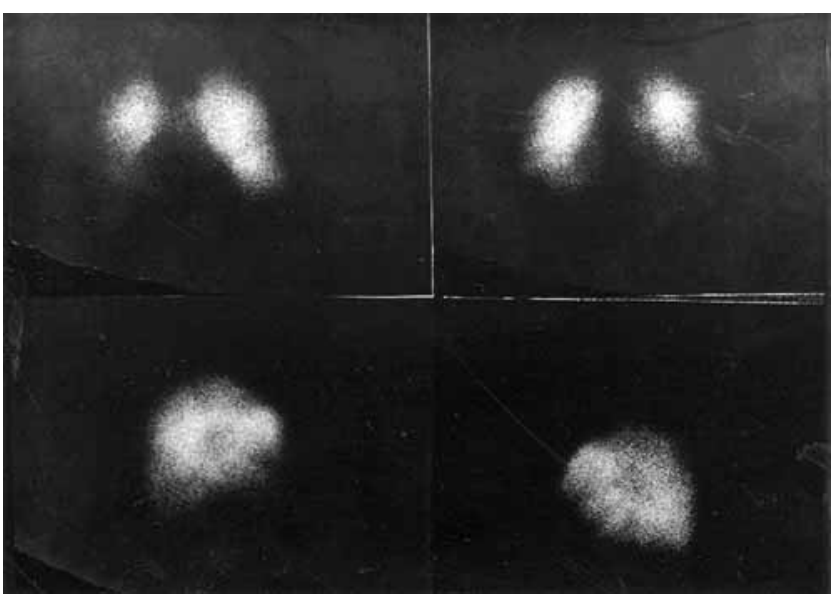

Рис. 3. Данные комплексного радионуклидного исследования легких с ${ }^{99 m}$ Тс МАА больной К. Локальное нарушение вентиляции, бронхиальной проходимости, диффузионной способности и капиллярного кровообращения в средней и нижней долях правого легкого.

вентиляции, бронхиальной проходимости, диффузионной способности и капиллярного кровообращения в средней и нижней долях правого легкого (рис. 3). Во время эндоскопического исследования в промежуточном бронхе справа обнаружено инородное тело (перепонка от грецкого ореха) с выраженным воспалительным валом вокруг, который почти полностью обтурировал просвет бронха. Инородное тело удалено с помощью биопсийных щипцов, проведен курс санационных бронхоскопий, проходимость бронха восстановлена.

У больных были извлечены следующие инородные тела: кости и куски мяса, кости рыбы, хрящ, семечки подсолнуха и яблок, фасоль, куски печени, дольки чеснока, лук, зелень, кусок перца, перепонка от грецкого ореха, веточка ели, фольга, куски стекла, кнопка, зубы и зубные коронки, пипетка. Размеры их вырьировались от 0,5 до 2 см.

У 5 пациентов во время диагностической бронхоскопии обнаружены кончик ножа (1), гвоздь (1), шурупы (2), колпачок от шариковой ручки (1). Извлечь их под местной анестезией не удалось, т. к. они были замурованы очень плотными грануляциями. Всем больным произведена ригидная бронхоскопия в операционной под общим обезболиванием, во время которой выполняли лаваж для отмывания гноя и грануляций, вводя в бронхи от 500 до 1000 мл раствора. В качестве антисептика использовали раствор фурацилина в разведении $1: 5$ 000, раствор риванола, раствор диоксидина и т. д. Под воздействием лаважной жидкости отек слизистой уменьшался, инородное тело постепенно освобождалось от грануляций и становилось доступным для захвата экстрактором. У 4 больных инородные тела были удалены.

Пациенту, у которого при рентгенологическом обследовании обнаружен кончик ножа, выполняли ригидную бронхоскопию, однако удалить инородное тело не удалось. Приводим наблюдение.

Больной М., 36 лет, поступил в больницу им. С.П.Боткина с диагнозом пневмония. При рентгенологическом исследовании органов грудной полости в нижнедолевом бронхе слева было обнаружено инородное тело - кусок лезвия ножа длиной 4 см (рис. 4). Как удалось выяснить из анамнеза, 3 года назад, во время банкета в ресторане, у пациента развился приступ эпилепсии, во время которого ему ножом разжимали зубы, и никто не заметил, что кончик ножа отломился.

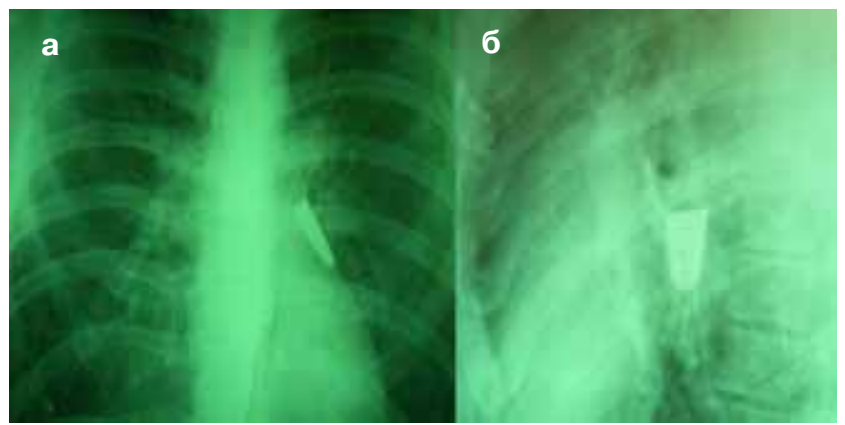

Рис. 4. Прямая (а) и левая боковая (б) обзорные рентгенограммы грудной клетки. В просвете нижнедолевого бронха левого легкого инородное тело - фрагмент лезвия столового ножа

Во время ригидной бронхоскопии под наркозом в левом главном бронхе виден проксимальный конец инородного тела, почти полностью скрытого мощными грануляциями. Произведен лаваж с введением до 1 л лаважной жидкости, однако даже с помошью мощных щипцов не удалось извлечь инородное тело - настолько плотно оно было зафиксировано в бронхе. Больному была выполнена операция; в ходе ее был обнаружен цирроз нижней зоны левого легкого, который был удален вместе с инородным телом.

После извлечения давно аспирированных инородных тел у всех больных сохранялись сужение и деформация бронха, грануляции на месте фиксации инородного тела. Впоследствии выполняли от 1 до 5 курсов санационных бронхоскопий. По окончании 1-го курса санационных бронхоскопий пациентам проводили бронхографию или КТ для оценки состояния бронхов длительно ателектазированного отдела легкого. У всех больных установлен диагноз деформирующего бронхита на основании следующих признаков. Мелкие бронхи, V-VII порядков, не суживались к периферии, а имели вид трубок одного калибра на всем протяжении. Контуры пораженных бронхов зазубрены, их очертания неровные. Просвет бронхов неравномерный: участки расширения чередовались с участками сужения бронха. Часть бронхов

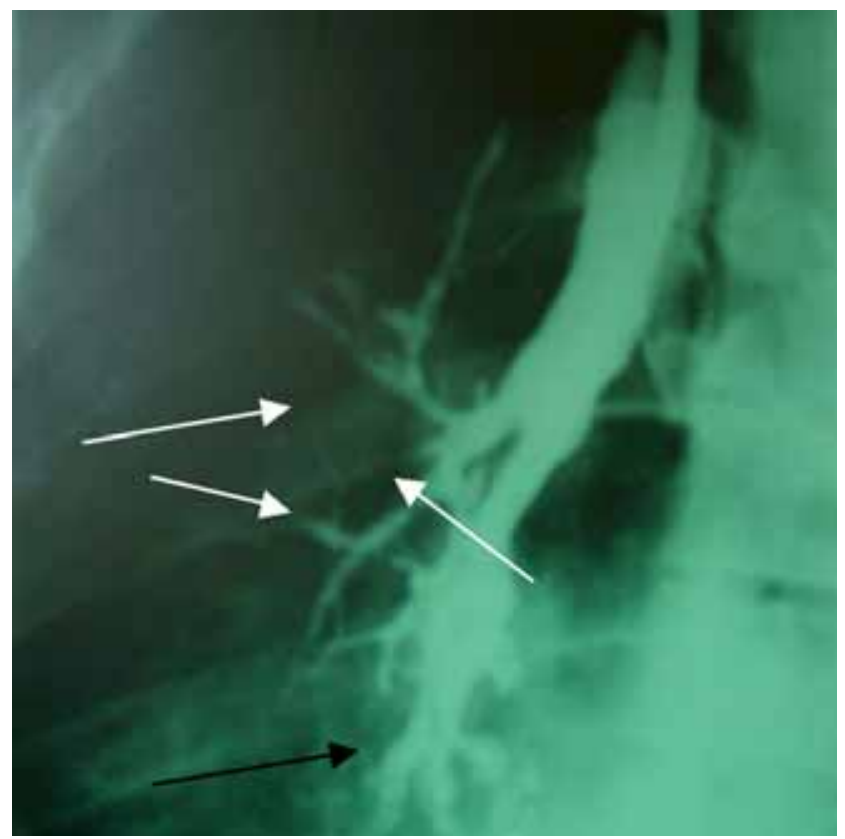

Рис. 5. Деформирующий бронхит. Мелкие бронхи нижней доли левого легкого деформированы, не суживаются к периферии, неравномерно заполнены контрастным веществом 


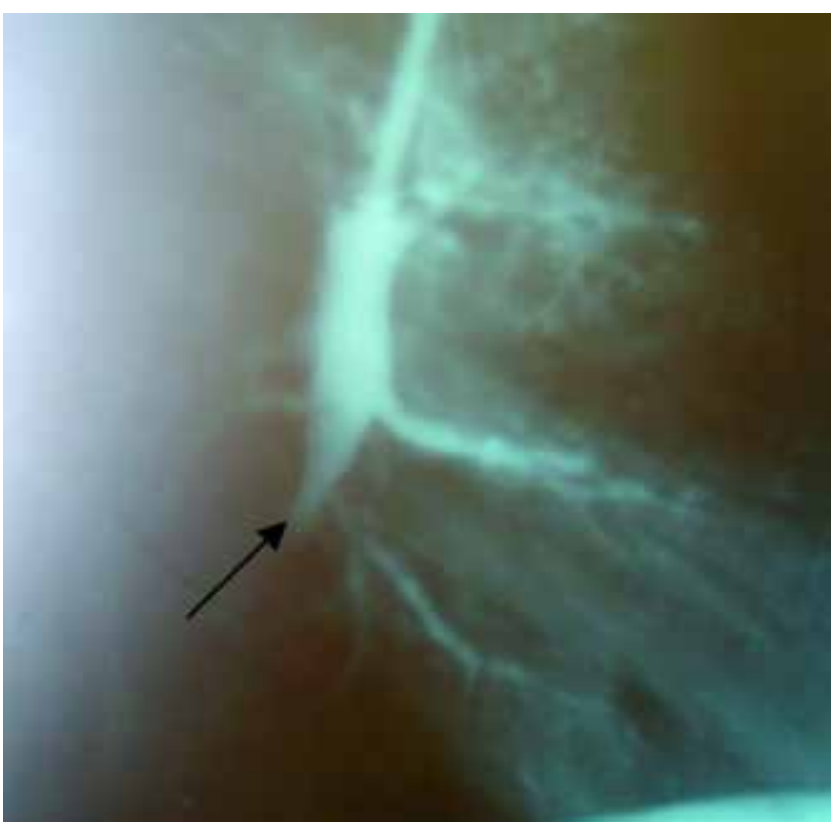

Рис. 6. Бронхограмма правого легкого (боковая проекция). "Культя" с неровным контуром общей ветви латеро-базального и передне-базального бронхов нижней доли правого легкого

IV-VI порядков не контрастировалась, причем они выглядели как бы обрубленными. Наиболее постоянный и характерный признак деформирующего бронхита - отсутствие заполнения мелких бронхиальных ветвей контрастным веществом (рис. 5, 6).

\section{Выводы}

1. 73,4 \% инородных тел бронхов нерентгеноконтрастны, поэтому при упорном течении хронического нагноительного процесса в легком и отрицательных данных рентгенологического обследования следует прибегать к диагностической бронхоскопии.

2. Большинство инородных тел бронхов различных размеров, формы и конфигурации можно удалять в амбулаторных условиях с помощью гибкого эндоскопа под местной анестезией.

3. Длительное пребывание инородного тела в бронхах ведет к развитию воспалительного процесса в легком, в частности деформирующего бронхита и стеноза бронха, что является показанием к проведению лечебных бронхоскопий после удаления аспирированного предмета.

\section{Литература}

1. Сотников В.Н., Чернеховская Н.Е. Значение бронхоскопии в диагностике и лечении больных с инородными телами трахеи и бронхов. Клин. мед. 1990; 5: 49-52.

2. Чернеховская Н.Е., Выренкова Н.Ю. Диагностическая и лечебная бронхоскопия при длительном нахождении инородных тел в бронхах. Грудная хир. 1990; 2: 52-57.

3. Чернеховская Н.Е., Андреев В.Г., Поваляев А. В. Лечебная бронхоскопия в комплексной терапии заболеваний органов дыхания. М.: МЕДпресс-информ; 2008. 110-119.

4. Чернеховская Н.Е., Федченко Г.Г., Андреев В.Г., Поваля$e в$ A.B. Рентгено-эндоскопическая диагностика заболеваний органов дыхания. М.: МЕДпресс-информ; 2007. 230-237.

5. Лукомский Г.И., Шулутко М.Я., Винер М.Г., Овчинников A.A. Бронхопульмонология. М.: Медицина. 1982.

6. Ремовский В.M. Последствия длительного пребывания инородных тел в бронхах. Вестн. хир. 1976; 3: 29-32.

7. Tarkka M., Antilla S., Sutinen S. Bronchial stenosis after aspiration of an iron tablet. Chest 1988; 93: 439-441.

8. Левитин B.A. Случай обтурации левого нижнедолевого бронха выпавшим зубом с развитием ателектаза. Вестн. рентегенол. и радиол. 1987; 3: 86-87.

9. Матвеенко В.А., Хасанов Л.Г., Темницкий Ю.М. Длительное пребывание инородного тела в трахее и правом бронхе. Вестн. хир. 1989; 4: 40.

10. Паращак П.В., Рыжих В.Н., Лазечко О.П. Редкие случаи инородных тел бронхов. Вестн. рентегенол. 1987; 4 : $85-86$.

\section{Информация об авторах}

Чернеховская Наталья Евгеньевна - проф. кафедры эндоскопии гоу ДПО "Российская медицинская академия последипломного образования"; тел.: (495) 945-05-35; e-mail: chernekhovskaya@mail.ru

Мальцева Ирина Михайловна - к. М. Н., ассистент кафедры эндоскопии ГОУ ДПО "Российская медицинская академия последипломного образования"; тел.: (495) 945-05-35; e-mail: irina-maltseva@mtu-net.ru Коржева Ирина Юрьевна - К. М. н., врач-эндоскопист ГКБ им. С.П.Боткина; тел.: (495) 945-05-35; e-mail: korg@rambler.ru

Поваляев Алексей Владимирович - врач-эндоскопист ГКБ № 52 Москвы; тел.: (499) 196-31-11; e-mail: povalyaev.alexey.@mail.ru

Макарова Галина Викторовна - врач-пульмонолог клинической больницы "Феофания" Государственного управления делами президента Украины; тел.: (044) 259-68-87; e-mail: feofania@i.kiev.ru

Поступила 19.01.09 () Коллектив авторов, 2009 удК 616.233-003.6-072.1 